\title{
The role of the ideological dimension in developing an anatomical approach to urban morphology: exploration of a new analytical method of open spaces network
}

\author{
G. Mohammed ${ }^{1,2} \&$ K. Thwaites ${ }^{2}$ \\ ${ }^{1}$ Cairo University, Egypt \\ ${ }^{2}$ Department of Landscape, University of Sheffield, UK
}

\begin{abstract}
Examination of the spatial organization of some historic city centres appears to show a more integrated relationship between the ideological dimensions of city life and the physicality of city fabric. When city planning and design development separates ideological and physical dimensions there is evidence to suggest that this can lead to detrimental impacts on the well-being and the physicality of the city fabric. This paper explores an analytical method that helps to understand urban spatial morphology and its relation to the ideologies of city life. Therefore, it analyses how the ideological model, as a collective of religious, political and cultural values lying beneath the physicality of the city, develop through three phases into aesthetical conventions. In this regard, the paper documents the agreements and disputes between people as an advanced step towards the refinement of these conventions. In this context, the authors explain the aspects of the conventions: the valuable, the tactical and the aesthetical aspects. In addition, they discuss how the tactical aspect, together with aesthetical aspect, plays the key role in maintaining social sustainability and characterize urban spatial morphology within this social sustainability. As a result, this approach contributes the planning education process by providing essential knowledge and the analytical base for the site analyses, design process of urban spaces and the conservation of urban fabrics in contexts that have multi layers of historic development. This exploration, ongoing at the time of writing, contributes to $\mathrm{PhD}$ research that will ultimately develop and describe a fuller anatomical approach for the analysis and design of such urban settings.
\end{abstract}


Keywords: ideologies, open spaces, quality of space, spatial, urban morphology, social forces, urban and building conventions, social sustainability.

\section{Introduction}

"Nature is not out there, a place apart from us. We have, instead, a continuity of humans and natural world. What we need now is to reconceptualise our world in a way that comes to terms with this, for what we do in environment we do to ourselves." (Berleant [5] p. 121). Cities, particularly in the Middle East and Southern Europe, have lost much of their quality of mix variety, and the fine urban grain of their legacy that contributes to street life and vitality. The dense and varied rhythm of traditional buildings, spaces or streets, now, are being replaced by larger residential and commercial developments. In this regard, a question arises; why and how did old cities sustain and survive throughout different historic periods creating great beauty and lasting quality without losing their functions and urban characteristics while many modern cities and new developments often seem to fail to achieve this. The possible answer has been found notably, in historic city layouts, of urban fabrics that appear to be much more ideologically responsive and in many ways a physical manifestation of the ideologies that were created to maintain social and urban sustainability. The present account explores how the urban forms of cities can survive naturally contributing to the urban spatial morphology within social sustainability. It establishes the core structure of an analytical approach to urban spatial morphology both as an academic discipline and professional activity aiming to re-conceptualize ideological values that have become increasingly separated from the physical form of the city, with physical urban morphology in a unified framework and forward to contemporary urban design. As such it contributes to aspects of urban design research and practice that seek socially sustainable solutions. In the context, and for more clarification, the new concepts will be shown in bold italic and the conventions in italic.

\section{The methodology followed}

The research has built up the conceptual framework of the anatomical approach, as a theoretical model, by identifying its two working models, through the following methodology; Firstly, the literature review and practical experience, help to determine definitions for the ideological and physical dimensions and then evaluates them to produce a provisional conceptual framework for the anatomical approach. Secondly, the components of this provisional approach are used to gather and analyse observational data using historic maps, mapping of spatial use, photos, visual and graphical analyses via the case study sites in Egypt, UK and a Latin European country. Thirdly, we proceed to the dissemination phase by discussing the approach's potential with professionals with responsibility for the design and management of open spaces to gain insight into how it might be able to be incorporated into local practices. 


\section{Developing the anatomical approach}

There are three phases constituting the approach. Phase one is defining the concepts of the anatomical approach. Phase two is the process of developing and producing the ideological model. The third phase is developing and producing the physical model. Then the body of this approach will be emerged via the mutual relation between the ideological model and physical model, which is called the Matrix, whereby applying the components of the ideological dimension with the components of the physical dimension determines the effect of the ideological dimension on the physicality of spaces and the physical dimension.

\subsection{Definition of anatomical approach}

The term "anatomical" is broadly accepted as referring to a metaphor from medical terminology "anatomy" because of the cross cut it makes through different layers beneath the surface of spatial form of the built environment to explore the relation between these hidden layers and the surface. Therefore, the approach taken will be to think of the anatomical approach as composed of two working models, the ideological and the physical. In this stage the research has analysed forces and ideologies that influence spatial morphology such as different ideological profile of each society like scale of publicness and privateness: (Carr et al [7]) socio-cultural, functional, political and religious forces. This leads to three main differences in the design ideologies of spaces; Latin spaces in South Europe, Western Europe, where spaces increase over time and the spatial concept is "space is a room to live in not a corridor to link", while the in Middle East, spaces decrease over time, therefore, the spatial concept is "space is a corridor to link not a room to live".

\subsection{Developing the ideological model of the anatomical approach}

The increasing interest in the comparative studies has demonstrated that both Middle Eastern and Western cultures believed in society's progress because of the notion of progress by an engineering society (Akbar [1]). However, the Western cultures believe in human rationality that controls that progress and decides what the most appropriate solutions for well-being are, then, these solutions could be delivered to the built environment, increasingly, any religious roles must come through the human rationality to be accepted. Therefore, professionals in Western cultures play a salient role to confirm this to deliver these appropriate solutions, this takes place, clearly, when the society moves from one paradigm to another such as Marxism/Capitalism, Structuralism/postStructuralism, Modernism/post-Modernism. Whilst the Middle Eastern cultures look further behind this rationality, which is the divine teachings. Accordingly, expression of the ideology in the built environment must be attached to specific value(s), whether these values are inferred from divine teachings or from the development of human rationality, in addition, the ideology must be attached to aesthetics, as an outer layer, to be effective (Lawrence and Low [11]). Thus the 
aesthetic is something that must be physical and visible that people can feel, taste and is pertinent to the concept of "beautification" of the visual image. By contrast, the value is the pragmatic approach that people want to achieve or apply in the built environment and their social life. In this respect, the development of values into aesthetical conventions passes via three phases. The first phase is the phase of emerging and expressing values to meet specific Need, and then people create, Creation, a solution to convene that need. Therefore, this phase gives the value to any act added to the built environment. The second is the tactical phase in which accumulative solutions created from phase one generate disputes or agreements that lead to the refinements for these solutions to reach to The ideal example. Then the tested ideal example is converted to be widely used as a Pattern. So, this phase maintains the spatial social sustainability. The third is the aesthetical phase, in which, if the pattern is proved, then it will gain its validity and credibility as a stated law to be generalized as a convention. As a result, the conventions can be perceived when people manage their built environment without real professional intervention or through professional practise, but have been provided with knowledge from societies' experienced in different forms such as the following.

\subsubsection{Religious conventions}

This form could be recognized when the space contained in religious buildings, walls, cemeteries, memorials, shrines, chapels, or other space is full of interactions and disputes between users that are responsible for any deformation in physical walling and the users' movement within the space as well. These conventions, therefore, organized the relation between people and buildings. Increasingly, they are concerned with how the built environment maintains the rights of the occupiers via two types; the first one is the religious conventions of that control social life and urbanism for local people such as no causing harm for the passersby, the right of objection of the passersby and the priority for the precedence to utilize and claim their area in market places. The second is the religious conventions that organize the reciprocal relationship between passersby and walls of space, official's urbanism, such as the conceptual relation of the window sitting recitation and the convention of "inside more holy than outside".

\subsubsection{Political conventions}

The physical structure of the city is an indicator of its political life, for example, tyranny is reflected in the heavy, imposing buildings, the formality, symmetry and monumentality of the structure of streets and open spaces. Therefore it is considered as an imposition of state over everything else (Zevi [16]). This means the space can be managed and controlled socially and politically by spatial means like signs, boundaries, fences, walls and gates or by temporal means, such as predetermined working hours (Madanipour [13]). In some cases, the authority deals with the facades and supervises the right way to maintain the urban character, such as what occurred in the block-long urban facades of many of the Amsterdam School apartment buildings dating from the 1920s and 1930s, or eliminates the role of individuals entirely, such as the case of Jules Hardouin Mansart in 1686, when he was employed by Louis XIV to build a public square 
from three sides, with the fourth side left open, and individuals' houses remained a part of the urban design of the square (Habraken [9]). As a result, there are two players controlling and integrating each other, the individuals and the authority. In this sense, sometimes, the decision is driven completely top-down whilst in other situations, the decision is estimated bottom-up. In addition, these examples highlight the technique of predesigned urban facades under supervision of the authorities or their representatives, such as architects. Accordingly, the political organizations of public spaces can be accounted of a group of democratic values as a horizontal spatial expression, including justice, egalitarian freedom, equality and tyrannical power, dialogue of political power, as a vertical spatial expression, including the control of public. These values play a crucial role in organizing and controlling the relation between the authority, the people and buildings within spaces (Grant [8]).

\subsubsection{Cultural conventions}

This form is concerned with the values that are generally understood as a set of habits and customs evolved to be roles that organize and control people's social habits and behaviours within spaces, such as the evening economy, and 24-hour economy or full/part-time space. The Western concept of evening space is due to the lack of use in the public realm during the evening with few activities to attract a broad range of social groups. The dead period in the city centre is between the end of the typical working day and the start of the night time when people return to the centre in search of the entertainment, which is known as the evening economy (Alexander et al [2]). As a result, the evening economy or evening space is criticized as being Male-Oriented and alcohol fixed with nothing to offer. Whereas in the Middle Eastern concept, the 24-hour economy is a Family-Oriented space creating a safer city centre, thereby alcohol prohibition is in place, and thus reflections have been found for these restrictions on the design and the shape of urban spaces, such as the location of openings and the gates of the space to ease the surveillance, the location and the type of spaces' furniture. In addition, there is continuity of the commercial activities in the evening, the full-time activities.

\subsection{Developing the physical model of the anatomical approach}

The literature in this section plays a significant role where it focuses on the approaches that analyse spatial morphology physically and is concerned with the socially responsive approaches as well. This assists the paper to establish the physical model. In this regard much is owed to the material of different studies, $[6,7,10,12]$. Consequently, developing the concept of the physical model has included three factors; the quality of space and multi layers of spatial modules, the space containments and the major morphological elements of spaces. Over lapping these three factors all together composes the body of physical dimension, then these three factors are re-organized in three groups to lay down the physical dimension as follows: the first group is Transaction Sphere, Edges and Flooring. These elements are influenced by the live load of space; as a result they are reforming the lower space, the inner space. The second group is 
Walling and Edges, which are affected by the dead load of spaces, so, are responsible for reshaping lower and upper space, outer space. The third group is Reference Point, Centre of Space, Transition Space, and Controlled Space. These elements are affected by live and dead load of space and responsible for reforming both lower and upper space. Then, the study has reconceptualised the two model's components in a provisional and unified framework via the analysis of the mutual relation between the two models to be forwarded to the case studies.

\section{Case studies}

The components of the provisional approach will be used in the analysis and conducting of three different case study sites from different design ideologies of spaces: Cairo, from the Middle East, Rome from Latin spaces and York, UK, from Western Europe.

\subsection{Middle Eastern case studies: space of Bein El-Qasrein - between the two palaces}

Cairo is considered as one of the biggest accumulative cities in the Middle East as it has multi layers of historic developments. Additionally, all political regimes that had governed this region were based in Cairo as a capital of the royal families; Fatimid, Ayypubid and Mamluk. Moreover, all of which yield a unique urban form causing transformations in the urban fabric. Consequently, the urban fabric of Cairo is considered as a an ideal prototype for all other urban fabrics in the Middle East, thus the research has tested different cases from different urban fabrics of Cairo; Medieval, Renaissance, and Colonial. In this context, the provisional approach has been applied in the medieval case to anatomize and analyse the spatial urban morphology in the light of social relations and traditional and religious exercises that existed - the reminder of the analysis of the cases is ongoing at the time of writing this paper.

This space here is the centre of the traditional city, which started as a planned space with the establishment of Cairo in the 960s; inside the royal palaces is categorised as a political space during the Fatimid period. Later on, it was transformed, functionally and physically, throughout different historic periods, fig.1, it shrank over time to be a street that highlights the Middle Eastern concept of spaces developments: the spaces became corridors to link not rooms to live". The base convention that was responsible for such transformations of spaces was the role of responsibility (Akbar [1]). It is based on removing any common or public land to private ownership, which enables people, whether they were elite or local people, since there was no any public responsibility towards the open space "vacant land".

\subsection{The anatomy of lower space}

According to the anatomical approach, the lower space is composed of outer space and the inner space; therefore, the first urban feature paid attention to, in 


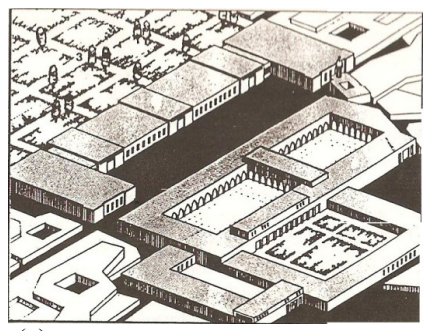

(a)

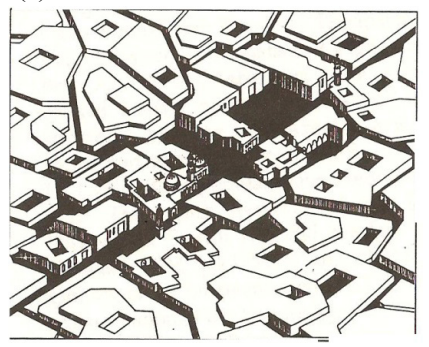

(c)

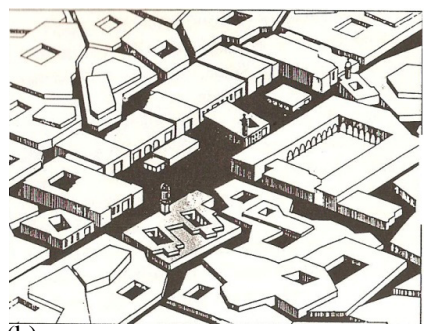

(b)

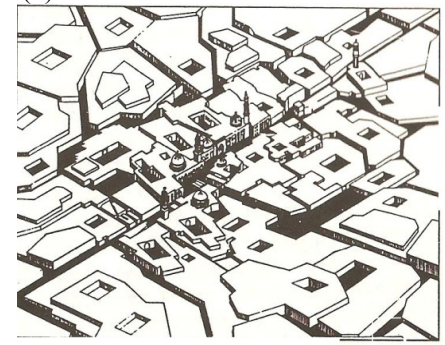

(d)

Figure 1: The transformations and the multi layers of historic developments. (a) Fatimid period 960s-1170s Royal space; (b) Ayyubid period 1170s-1250s military and educational; (c) Mamluk Bahri period 1260s-1370s commercial and educational; (d) Mamluk Burji and Ottoman period 1380s-1830s commercial and educational space (AlSayyad [3]).

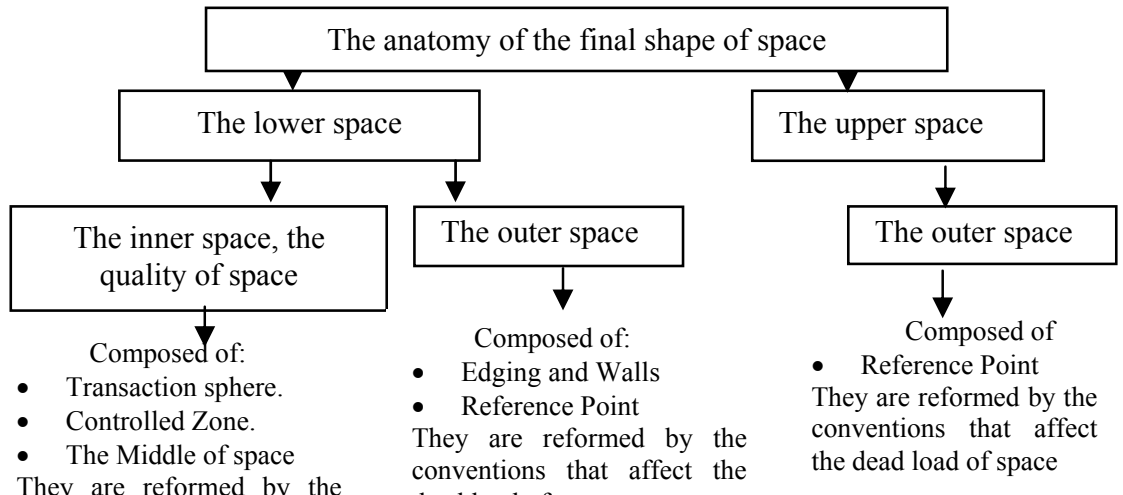
conventions that affect the dead load of space

Live load of space

Figure 2: The anatomy of spaces according to the anatomical approach. 


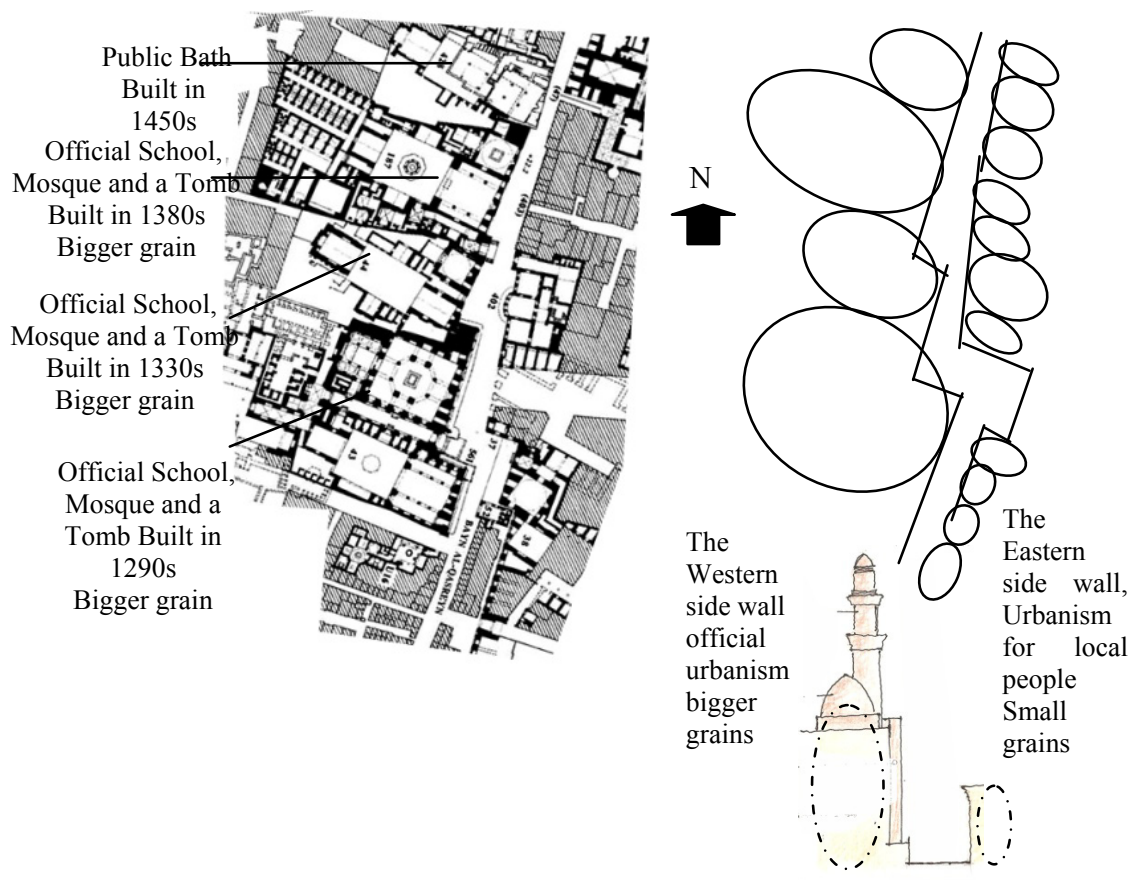

Figure 3: The dialogue of political power between buildings adjusting and opposite each other in space or between the western side and the eastern side of space. Source: the authors.

the outer space, is the bigger size of the urban grains in Western walls than Eastern ones, fig.3. This means that all the surroundings are official buildings, thus the morphology of this space was controlled by its dead load or, in another meaning, it is regulated by its walling and edging rather than by its live load or the inner space, fig.2. Furthermore, the pattern that prevails the relation between its walls is the dialogue of political power expression. This dialogue is evident in these massive urban grains, which were built from different authorities in different eras and is best illustrated when it organizes the relation between buildings adjusting and opposite each other. This is obvious in the dense and extensive architectural expression that appears in the walls of this space and is best for expressing the tyranny and monarchy of political authority, fig.3.

This ideological dialogue, in Middle Eastern cites, organized the walling and edging of space through various conventions. The first one, from practise based work, is the Window Sitting Reciter. This relation played a key role in reforming this space because of the reciprocal relation between buildings and passersby; therefore, it reformed also the transaction sphere of the inner space. In this relation, the traditional designer was asked to impose the tomb of the king into the space - traditionally the tomb was an essential part of any official complex 
inside the city. Then the relation starts with the man who was employed to recite the holy book to attract the passersby closer, to the window of the tomb. This, as mentioned, required the tomb to be located imposing the passage way of people in the space. Additionally this tomb should be located in front of the prayers hall which, in turn, had to be located towards the direction of Muslims' Qibla, fig.4. All these religious constraints directed the designers to the western side as suitable sites to build all these adjusted complexes, however the authorities, at that time, were able to claim any other sites in the city.
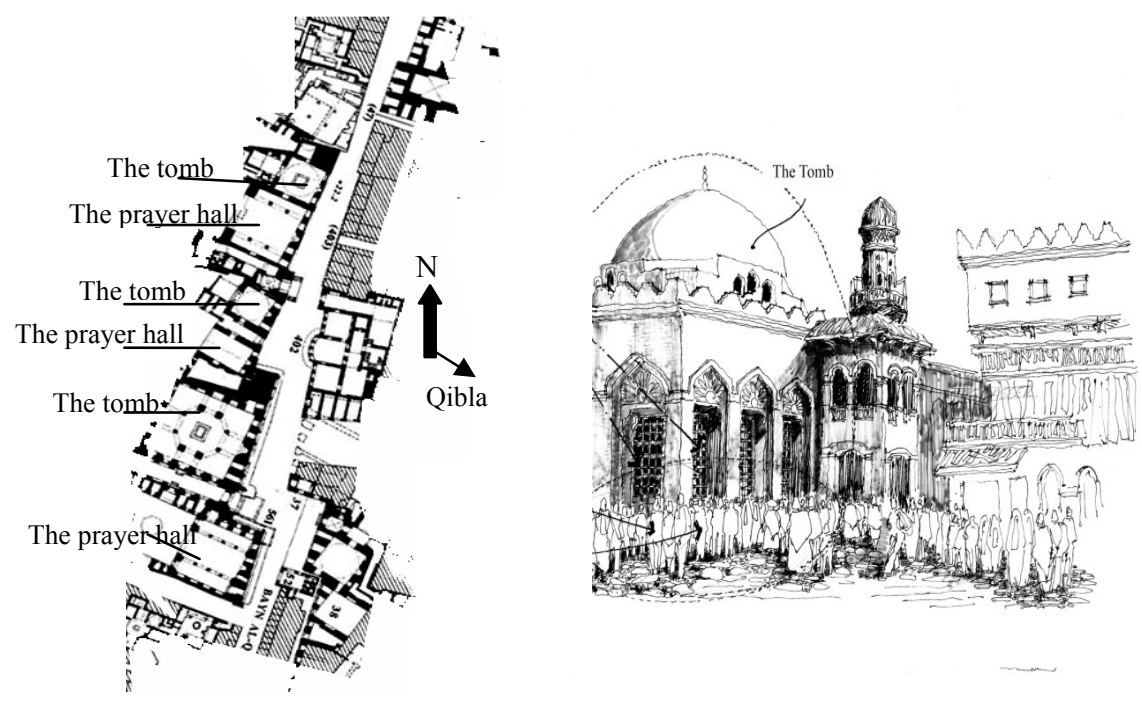

Figure 4: The religious conventions, the relation of window reciter, did reform the dead and live load of urban space. Source: the authors.

The second one is the use of water inside space, which was fundamental because it is religiously preferable to the water used by the poor, since they could not afford cisterns in their homes and it was a pious act for the elite to endow places for free drinking water. In addition, the upper floor was a Kuttab, a school where children learned to recite the Qur'an. Such buildings, called Sabil, were a favourite charitable endowment and were a common spatial feature where they were attached to the walls as the convention behind this was the avoidance of harm where no causing harm for the passersby. Therefore, it was religiously advisable not to put any obstacles in the passage way; moreover, the middle of the space belonged to the passersby, not to the fountain or the Sabil, causing the building line to be movable and dynamic in shape, fig.5.

\subsection{The anatomy of the upper space}

This is only concentrated on the outer space. Therefore the analysis in the upper level starts from the reference points, represented in minarets and domes that the 

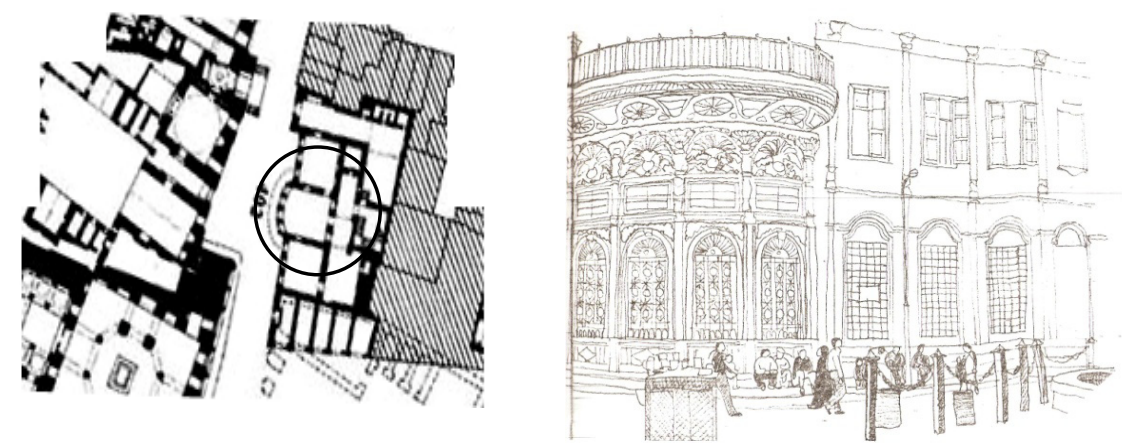

Figure 5: The curvature of the Sabil's wall, causing its moveable and dynamic pattern of the dead load and heavy decoration causing passersby to stop compelling and water themselves and the image Antoniou [4].
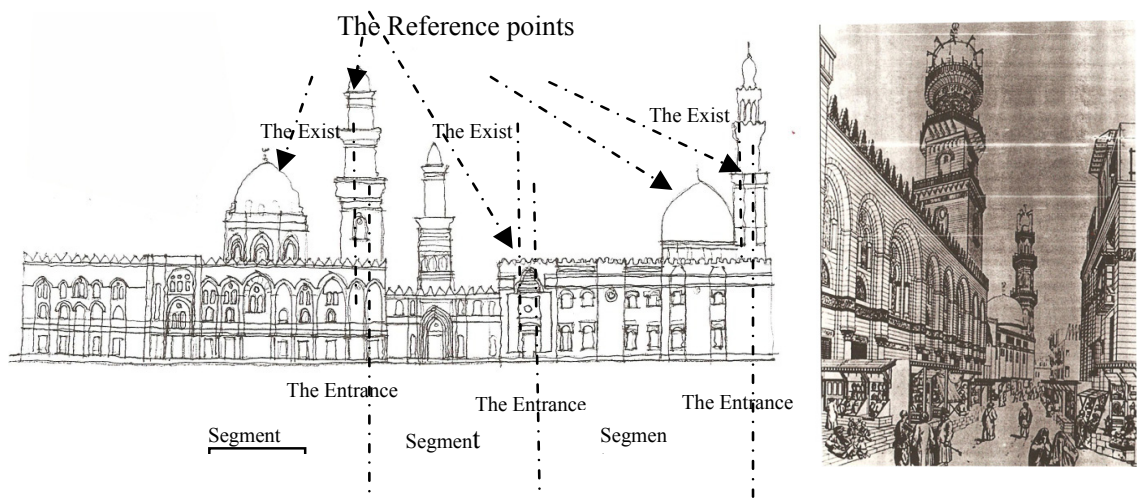

Figure 6: The reference points of the western wall divide the space into segments each of which start with an entrance and end with an exit in the same segment. Source: the authors and the image Coste [17].

space contains. Additionally, the linear shape of space gives the directional sense of In-Out that is generated by these various reference points that are responsible for the feeling of arrival or existence as the concept of hereness and thereness (Thwaites and Simkins [15]), but it gives an additional spatial aspect; the directional movement between In and Out. That is because it gives spatial experimental starts from the feeling of space of the Entrance as the sense of In, the feeling of space of the Exit as the sense of Out in order, fig.6. Then, the spatial experimental is renewed as the exit has become the entrance for the following segment and so on. Consequently, it is conceptualized into OriginDestination Reference, which is controlled by different religious convention such as the Sofis Principle that controls and reforms land marks and vertical elements such as minarets, domes and political conventions, for example Planning or 
Division Conventions and Building and Facades articulation Conventions - this will be explained in more detail in an extended version of this paper.

\section{Conclusion}

Examination of any open space shows the importance of the hidden factors, ideologies that lie behind the physical aspects of spatial morphology. This means that the spatial form is reshaped not only by its physical features, but also by its collective of religious, political and socio-cultural characteristics, which conceptualized by this paper into the ideological dimension. Therefore the main contribution of this paper is the exploration of the two working models, ideological and physical, together through matrix relation, constituting the provisional framework of the proposed approach that is considered as an analytical method that enables practitioners and academics to understand at a deeper level the anatomy of spatial form as an advanced step towards the design process of open spaces. In addition, the base concept of the ideological model depends on the development of the aesthetical conventions that are varied between religious, political and cultural. These conventions have a salient impact on the spatial form that is different from culture to culture according to the dominant ideology. Finally, ignoring the hidden ideologies in the analysis process of spatial morphology means ignoring the bottom-up decision, which leads to a devastating impact on social sustainability, which in turn negatively affects the inhabitants and the physical form.

\section{References}

[1] Akbar, J. A., Responsibility and the Traditional Muslim Built Environment. Architectural Press, Massachusetts, M.I.T, 1984

[2] Alexander, C., Ishikawa, S., Silverstein, M., Jacobson, M., King, F. I. \& Angel, S., A Pattern Language, New York: Oxford University Press, 1977.

[3] AlSayyad, N. Biyn Al-Qasriyn: The street between the two palaces, in Celik, Z., Favro, D. and Ingersol, R. (eds.) Streets: Essays in Urban History. Berkeley: University of California, 1995.

[4] Antoniou, J., Historic Cairo: A Walk through the Islamic City, American University in Cairo Press, 1998.

[5] Berleant, A., Living in the Landscape: Toward an Aesthetics of Environment. Kansas: University Press of Kansas, pp.121, 1997.

[6] Carmona, M., Heath, T., OC, T., Tiesdell, S., Public places Urban Spaces: The dimensions of Urban Design. Architectural Press, An imprint of Elsevier Science, Oxford, 2003.

[7] Carr, S., Francis, M., Rivilin, G.L. \& Stone, M.A., Public Spaces, Cambridge: Cambridge University Press, 1992.

[8] Grant, J., The dark side of the grid: power and urban design. Planning Perspectives, 16, pp. 219 - 241, 2001.

[9] Habraken, N.J. The Structure of the Ordinary, the M.I.T press, Cambridge, Massachusetts, London, England, 1998. 
[10] Hillier, B., Space is the Machine, Cambridge University Press, Cambridge, 1996a.

[11] Lawrence, D.L. \& Low, S.M., The Built Environment and Spatial Form. Annual Review of Anthropology, 19(1), pp. 453-505, 1990.

[12] Llewelyn, D., Open spaces networks of greenways between new and existing urban areas. Urban design compendium, English Partnerships, pp. 54-58, 2000.

[13] Madanipour, A., Why are the design and development of public spaces significant for cities? Environmental and Planning B. Planning and Design, 26, pp. 879-891, 1999.

[14] Sitte, C., City planning according to artistic principles, London: Phaidon, 1965.

[15] Thwaites, K. \& Simkins, I., A prevailing world view, Landscape as place, Experiential and Spatial Dimensions, The vocabulary of experiential Landscape, London, Routledge, 2007.

[16] Zevi, B., Architectural as Space, New York, Horizon, 1957.

[17] Exterior of the Mosque of Qalaoun, Cairo', engraved by Auguste Hibon (1780-1857) 1829 (litho), Coste, Pascal Xavier (1787-1879). Bridgeman, Art and Culture History, Website http://www.bridgemanart.com/ 